\title{
Place branding sports: Strategies for differentiating emerging, transitional, negatively viewed and newly industrialised nations
}

Received (in revised form): 26th October, 2006

\section{Irving Rein}

is a professor of Communication Studies at Northwestern University. He is the coauthor of Marketing Places: Attracting Investment, Industry, and Tourism to Cities, States, and Nations (1993); the latest Marketing Places book, Marketing Latin American and Caribbean Places (2006); and The Elusive Fan: Reinventing Sports in a Crowded Marketplace (2006).

\section{Ben Shields}

is a doctoral candidate in the Department of Communication Studies at Northwestern University. His research is in the area of sports and technology. He is the coauthor of The Elusive Fan: Reinventing Sports in a Crowded Marketplace (2006).

Abstract Places have long sought a defining image to drive their economic and social initiatives. Many of the branding strategies have been examined extensively and utilised in the marketplace. For emerging, transition, negatively viewed, and newly industrialised nations considering the possibilities for differentiation, a relatively underused positioning is incorporating sports into the branding mix as both a primary and secondary tool. There are a number of specific strategies that can be used to implement this initiative, and the authors explore and analyse these sports place branding possibilities.

Place Branding and Public Diplomacy (2007) 3, 73-85. doi:10.1057/palgrave.pb.6000049

Keywords: Sports, sporting events, teams, branding platforms, place branding

Correspondence: Irving Rein, Department of Communication Studies,

Northwestern University, 1815, Chicago Avenue, Evanston, IL 60208, USA. Tel: +1847 4915851

Fax: +18474671171 e-mail: i-rein@northwestern.edu

\section{INTRODUCTION}

The global marketplace for place branding has never been more competitive. Places both established and emerging are under increasing pressure to attract and retain residents, tourists, and investors in a rapidly globalising and fragmenting marketplace. The demand for the most effective place brand-building strategies has never been greater, and for many places with only a limited amount of resources, difficult choices must be made on which brand strategies to implement.

The problem is that many of the strategies to compete are becoming stale and require innovation. For example, it was innovative 50 years ago to segment and target tourists in a systematic manner. During the past half century, places have refined their tourist bureaus on local, regional, state, and national levels and added facilities and attractions, all to capitalise on what has arguably become the world's largest business (World Travel \& Tourism Council and Accenture, 2006). ${ }^{1}$ Another strategic shift occurred in the 1970s, when countries all over the world began to compete for business attraction, which often resulted in a zerosum game. What began in the United States as an exodus from the traditional steel, automobile, and clothing industries 
became a worldwide trend where the highest bidder often got the company, the jobs, and the sometimes temporary glory of running a plant.

In today's environment, many countries are competing in the service economy as places like India, China, and the Philippines are able to provide state-of-the-art technology services that were previously home bound in the first-world countries. Many of these new developments, which include editorial services, booking agents, and accounting support, have only recently become global trends. The strategy of highwage countries such as the United States, England, and Germany of building premiere educational and technology training institutions is being challenged by lower cost competitors who have the language, technology skills, and the ability to price below market.

These initiatives are not obsolete and will remain a part of the place attraction arsenal. After all, in many instances they have worked, and as a result, many places have become destinations or economic powerhouses on the basis of these strategies. Countries, however, need to develop new ideas and perspectives in order to survive in a marketplace as volatile as this one. For example, the constant rotation of higher priced manufacturing and services to an ever-lower wage base threatens all countries except the current winners. In the everchanging tourist marketplace, destinations that own traditional market shares find themselves being challenged by newcomers who industrialise previously undeveloped historical sites, add theme-based attractions, or reposition to catch the latest cultural wave. In today's marketplace, no country is safe, and there is a continuous need to both innovate and answer the challenges of a competitive marketplace.

\section{THE SPORTS SOLUTION}

While there are a number of possible solutions to generating and communicating a strong and coherent place brand, this paper will explore the significance of sports as a place branding platform for emerging, transition, negatively viewed, and newly industrialised countries.
In doing so, the importance of investing in sports as a component of a place branding plan is discussed. Furthermore, for some countries sports can serve as a central platform rather than as a supplement to a branding initiative. As the sports industry continues to grow and globalise, place brand managers and marketers must adjust to and capitalise on what has become an ever-expanding paradigm - the sports economy.

This proposal may at first seem unrealistic to some places given the resources required to invest in sports and the many other challenges such as education, transportation, and healthcare facing them. In addition, emphasising sports in any branding plan may appear to be a losing game when considering that many of the strongest sports programmes are those of firstworld countries who have the financial ability and historical capital to invest heavily.

Despite these reservations, sports can provide places with both tangible and intangible benefits. Sports receive widespread free media coverage, which generates valuable visibility that can attract tourists, residents, and investors at a low cost. Sports also stimulate an emotional heat between the participants and the audiences that can symbolise the energy, vigour, and strength of an emerging nation in ways that eco-branding, museums, and other cultural attractions cannot. Another benefit is that sports provide the local residents and companies and institutions considering relocation with an environment of variety and competition that promises an engaging place to live. Moreover, sports competition fosters common bonding, which includes places for residents to share their experiences and the accompanying healthy tensions and uncertain outcomes that encourage identity building.

Sports have often been an integral part of a nation's identity. The Olympics are one of the defining attributes of Ancient Greece and the Coliseum in Rome still stands as a symbol of the sports and entertainment culture of the Roman civilisation. It is, however, only been in the last several decades that places have begun to use sports strategically to promote their 
brands. For example, Schimmel (2001) examined how Indianapolis transformed from an industrial city into a tourist and business attraction by building sports facilities and hosting sporting events, and Kerr and Johnson (2005) demonstrated how the town of Bargo decided to become 'Australia's cycling town' in an attempt to reverse its historically negative image. Smith (2005) has studied the cases of Birmingham, Manchester, and Sheffield and how sports initiatives have impacted these three cities, and Brown et al. (2002) have discussed the Sydney Olympics and its implications for the Australian brand. The general focus of these studies and others in the field is to explore the effects of sports on the development and distribution of a place brand, and all of them have made important contributions to the understanding of place branding.

Despite the growing academic interest in this subject, there is still a need for work on the strategic use of sports as a branding tool for countries other than the industrialised and established ones. Therefore, this paper will focus on the rationale, strategies, and implementation of branding these nations with sports. First, a perspective on the evolution of sports and place branding will be discussed. Next, three place brand platforms will be examined for their fit to a place's brand. Finally, the paper will offer a framework for how to approach and implement a sports place brand initiative. In the end, having a championship rugby team or goldmedal marathon runner is not enough. Successful sports place branding on a global stage requires follow-through and a coordinated and coherent brand plan.

\section{THE EVOLUTION OF SPORTS AND PLACE BRANDING}

The history of branding countries through sports is marked by spectacular results, promising fits and starts, and self-serving manipulation. There is arguably no better example of the potential power of the relationship between sports and place than New Zealand. In the early 20th century, New Zealand branded the All Blacks, its national rugby team. The team travelled frequently to take on and beat the best of the British Isles. In wearing their ominous black uniforms and silver fern logo and conducting their fearsome Haka opening game ritual based on the Maori culture, they began to invent a brand for this faraway English colony. The All Blacks put a face on its country and still remain an integral part of its identity (Jackson and Hokowhitu, 2002; Hope, 2002). The team was not only a winner but symbolised the independent, adventuresome, and rugged persona of the country. Sports have the ability to transmit emotional energy and qualities of competition and dedication that no other endeavour can emulate, and the All Blacks became a symbol of New Zealand's emergence as a brand with assets and a people to match.

Similar efforts have been attempted over the decades, with some countries experiencing sustained success and others only temporary recognition. For example, the Scandinavian countries have branded skiing, the Dutch speed skating, and the Japanese sumo wrestling. In the case of India and Pakistan, cricket has become not only the dominant sport but has overshadowed the home country of England in importance and crowd appeal. Kenya became known as a running empire as early as the 1960s, and its great runners dominated the long distance races at the Olympics and other world events. All of these countries are associated with their sporting achievements and in one way or another have benefited. While the Kenyans have benefited from their stars returning to the homeland and investing in the country, they are inconsistent in the development of their running programme and have not fully capitalised on the power of the branding appeal of their international runners (Macharia, 2005). In contrast, Norway has integrated their winter sports expertise into producing not only sports stars but also clothing lines and tourist attractions.

Sometimes sports have been used as an instrument to reshape perception, and not always in the most ethical manner. In a backhanded compliment to the power of sports 
branding, Nazi Germany in the 1930s and the Soviet Union during the Cold War sought to impress the world with their sports dominance. The 1936 Berlin Olympics, captured by Leni Riefenstahl (1938) in her documentary Olympia, was an attempt by the Nazis to imprint German athletic superiority on the globe. The Soviet Union bloc saw themselves in a dual of nations with the United States and extended their battle to sports, competing successfully over several decades, despite widespread criticism of drug use. These two examples are reminders that sports can be an instrument of political oppression and used unfairly and unwisely by governments. These dangers are always present in any combination of sport and state and should be heeded as demonstrated by the recent soccer match-fixing allegations in Germany (Kammerer, 2006) and Italy (David, 2006). ${ }^{2}$ Despite these admonitions, sports are now part of a larger global economy and are ignored only at the peril of a place seeking development.

What has happened in sports is that technology and globalisation have given places access that they have never had before. The configuration of the worldwide television networks, internet, and wireless networks has exploded, and in the process, sports have been one of the greatest benefactors. Day or night, fans can see or hear their favourite team no matter where they are in the world. Further, many sports have established universal appeal as they move from their traditional home countries to places all over the world. The United States-based NBA is making major inroads in Europe, China, and most of the globe. Originally European- and South American-based, FIFA has not only invaded the United States but has made a major commitment to the Asian sector to build up its global empire. Cricket, once considered only an upper class colony sport, is televised globally and as a consequence has compressed its game to appeal to markets that were unlikely to watch the traditional five-day match marathon. What was once a tightly configured sports universe now amounts to hundreds of billions of dollars in value with an emerging country like China alone predicted to have a sports market of $\$ 10$ bn by 2008 (Agence France Presse, 2005). Whether it is Formula-1 cars zooming around an exotic track in Malaysia or a Bulgarian table tennis star emerging on the international scene, sports are everywhere and consumed by an ever-growing and freespending public.

\section{ARGUMENT FOR SPORTS INVESTMENT}

Despite the expansion of the sports industry, investing in sports facilities and teams has been an unresolved issue for places around the globe. At this point, the investment question has been relatively understudied, and the research that does exist often offers inconsistent conclusions. For example, in the United Kingdom, there is a growing body of evidence suggesting that hosting sporting events contributes positive economic values to place branding initiatives. For example, a report by the Sport Industry Research Centre (UK Sport, 2004 cited in Gratton et al., 2005) entitled Measuring Success 2: The Economic Impact of Major Sport Events synthesised the data from 16 studies on the economic impact of sporting events in the United Kingdom. The consensus finding was that cities received a substantial increase in economic activity as a result of hosting their events.

In contrast to the United Kingdom's research, almost every economic study examining the financial implications of public funding for facilities of professional sports teams in the United States (eg Quirk and Fort, 1992; Noll and Zimbalist, 1997; Rosentraub, 1997) has concluded that cities and their taxpayers do not consistently receive the benefits that owners and politicians promise. While job creation, improved housing, downtown re-gentrification, and an overall positive impact on the local economy have been popular appeals to the public for funding, the evidence suggests that the returns on taxpayer investments do not always justify the significant expenditures. 
Yet places in the United States continue to take the financial risks to build massive stadiums with public money. In Minneapolis, Minnesota alone, a city in a state of only 5 million people, two new stadiums are being built with a combined cost of more than $\$ 750 \mathrm{~m}$, which taxpayers are responsible for varying contributions depending on their jurisdiction (Kaszuba, 2006a, b), ${ }^{3}$ and there are negotiations for a third with a likely price tag of at least a half billion dollars (Pabst, 2006). ${ }^{4}$ Resolutions for the two stadiums passed despite a raging battle for years as opponents threw up numerous roadblocks citing the draining of financial resources from education, health, and other infrastructure needs. This scenario was repeated time and time again in cities all over the United States, but still resulted in a sports facility construction boom across the nation. Since the beginning of the 1990s, at least 25 of the National Football League's 32 teams have either remodelled their stadiums or built brand new ones (Frangos, 2004), 20 new Major League Baseball Stadiums have been constructed (Ballparks of Baseball, 2006), and 24 National Basketball Association teams have moved into new arenas (Hoops Corner, 2006). In the same time period, at least 50 per cent of Division IA university and college football programmes have built a new stadium or made significant renovations to their existing one (Litan et al., 2003), and this trend has even reached American high schools, with an estimated $\$ 440 \mathrm{~m}$ worth of new facilities built in 2004 alone (Menez, 2005).

These are huge investments in sports, and given the results of many economic studies, why are places still willing to risk hundreds of millions of dollars on sports when they are choosing among many other pressing needs? An answer is that the communication and marketing benefits that a place derives from having sports facilities and teams make the investment worth it. If Minneapolis did not have its major sports teams and a Division-I university programme, it is safe to say that its visibility as a city would be reduced significantly. What price can be placed on a favourable image that has global implications? What are the sports teams worth to a company considering moving to Minneapolis? What dollar value can be placed on the residents' pride and civic engagement with sports teams? What is the worth of a box score for a baseball team that appears in every media outlet daily? These are the important, but often intangible benefits that accrue to a sports branding programme that cannot always be quantified. Sports branding at its base is about people and their relationship to their place, and there is virtually no substitute for this connection.

Whether it is Minneapolis, a first-world city struggling with prioritising its place branding initiatives, or Senegal, a third-world country trying to not only stabilise its political and economic situation but also reverse long-held perceptions about its nation, all places face the same problems of deciding how and where to spend their resources. If a place decides to invest in sports, it needs to understand the branding possibilities.

\section{SPORTS AS A PLACE BRANDING PLATFORM}

An effective place branding strategy requires a platform that can communicate its identity and assets to its target markets. If a place chooses a sports initiative to brand itself, the possibilities include the event, team, and place platform. While the resources required to implement each vary, they are intended to offer the range of possibilities for emerging, transition, negatively viewed, or newly industrialised nations to consider in their efforts to break out in the marketplace.

\section{Event platform}

Hosting a sporting event is the current state best practice of sports place branding. Places have historically seen these opportunities as windows into their economy, culture, and health and a chance to reposition the brand. Events can be one-time occurrences such as the Olympics or the FIFA World Cup or annual occurrences such as a professional golf tournament or a road race. In the best cases, such as Sydney, Australia hosting the 2000 
Olympics, it can be an unqualified triumph delivering tourist dollars, investment, and a tremendous lift in self-esteem to this relatively isolated continent (Brown et al., 2002). The event, however, does not have to be of such a magnitude for a place to benefit from sports. It can be staging the junior championships in track and field like the sports branded city of Indianapolis, Indiana has done or the hosting of a regional professional golf tournament in Thailand.

A compelling example of rolling the dice on an event platform was the decision of the Chinese government to pursue and ultimately land the 2008 Olympics. The Chinese are determined to use the Olympics as a window into their progress from a third-world country to a powerful free market economy. In doing so, they are constructing new sports facilities, public transportation infrastructure and a terminal at the airport that will cost $\$ 40 \mathrm{bn}$, a number that far exceeds the $\$ 12 \mathrm{bn}$ the Greeks spent for the 2004 Olympics (Kranhold and Fong, 2006). At the same time, they are wrestling with a massive pollution problem, potential transportation nightmares, civic and civil issues of behaviour, and a reputation as an authoritarian government with little tolerance for free speech (Xiangwei, 2006; Dickie, 2006; Batson, 2005). While it may be optimistic to think that a successful Olympic staging will resolve all of these issues, significant progress in a global showcase can jumpstart a reinvention.

There is more to the Chinese attempts to brand sports than the Olympics itself. All over the country, there are sports teams and junior programmes intended to create Chinese excellence in a wide range of sports. The tennis world was startled when $\mathrm{Li} \mathrm{Na}$, a product of China's drive to establish a sports identity, emerged at Wimbledon with little fanfare and a powerful ground game (Roberts, 2006). The shoe company Li Ning, a heretofore weak competitor to Nike and Adidas in the basketball shoe market, has ramped up an extensive star campaign for a relatively obscure US basketball player (Kang and Fowler, 2006). This campaign is of importance as it throws down the gauntlet to countries such as the United States and Germany that not only is China going to launch events but it will also build stadiums, develop world class athletes and outfit them with their own branded sports gear. All this more deeply roots the Chinese sports event strategy and all the necessary ingredients to support such an elaborate branding effort.

While there is often more risk with the event platform, its rewards can be greater. The amount of free media coverage in a relatively short and focused period of time is an opportunity for the country to promote itself and its assets to potential buyers. An additional advantage of the event platform is that it is an opportunity for places to invest in infrastructure improvements that are designed to benefit the country after the event. On the critical issue of social impact, events can also serve to bond the residents of the place through pride and investment of time and real and emotional energy.

Of course, the downside to any event platform is that places can be unprepared for the attention and rather than serving as a coming out party, it becomes an indictment of the place's problems. Moreover, some places, such as Greece (Miller, 2005), find themselves with investments in facilities that are not financially stable or usable in the future. As a result, this requires careful consideration of any opportunity and that the audit and analysis of strengths and weaknesses are done with realistic expectations.

\section{Team platform}

There are two different types of team platforms: the privately owned teams that are named after a place and the national teams that are controlled by the place itself. In either case, it is often the task of the place to cooperate in helping build facilities, participating in joint marketing campaigns, and facilitating the relationship so that the teams have friendly environments. In many cases, teams transcend private ownership and become magnets for tourism, business attraction, and resident retention. Stellar examples of that model are 
the New York Yankees in the United States and Manchester United in England, which have helped build the brands of their places through their global reach. Manchester United has become a global brand with approximately 75 million fans worldwide (Scott, 2006), and in doing so, it is bringing visibility, income, and star power back to the home city. Other soccer teams such as Chelsea and Real Madrid are following a similar strategy and creating global appeal through star power and new technology. In cities like Toronto and Montreal in Canada, the professional hockey clubs - the Maple Leafs and Canadians - are the most sought after tickets in the cities and serve not only as a magnet for the winter season but as the critical identity for the country itself.

The private team platform has set off major attraction wars in some cities. While in the earlier part of the 20th century it was considered an asset to have a well-known sports team, it was not until the rise of television and the increasing emphasis on place attraction and tourism that the addition of a sports team was a central element of a place brand. In the United States, for example, Milwaukee, Wisconsin has lured a professional baseball team from Boston, lost it to Atlanta, and then managed to convince Major League Baseball to grant them the Seattle franchise that was originally lured from Washington DC. All of these relocations were driven by the host cities' belief that both their place identity and revenue possibilities would increase with a Major League Baseball team. The obligation of building stadiums and roads and adding other inducements are generally seen as part of the overall place's branding effort.

While place brand managers have little control over the management of a private team, an emerging strategy is for places to brand the publicly operated national teams as if they were private enterprises. For example, the Brazilian national soccer team has become a major platform for the country to export its culture to potential tourists, residents, and investors. During the 2006 World Cup, the Brazilian soccer federation launched what was termed the
Culture Cup (Copa da Cultura), using the team as the springboard to showcase Brazilian art, film, and other parts of its culture. The Culture Cup also borrowed the star power from former national team player, Pele, who was symbolic of the Brazilian athleticism, grace, and samba beat (Xinhua General News Service, 2006). In this example, the Brazilians are capitalising on the visibility and reach of their national soccer team to inform potential markets about its country and culture.

The Ghana national soccer team, the Black Stars, which were noted for their style and playing ability in the 2006 World Cup, is another case of a team platform. Ghanaians were glued to their television sets as the entire country stopped to watch the team play against the world's powerhouses such as Brazil, the Czech Republic, Italy, and the United States. The country was on every media channel in the globe with millions of people asking questions about it.

Ghana, with a population of 22 million, of which more than one-third cannot afford to spend $\$ 1$ per day to live (The Economist, 2006), was suddenly in the international spotlight. Significantly, a country with a dominating junior international programme was finally stepping up at the senior level for the first time, and as a result of their World Cup success, they experienced a visibility bounce. For example, Graphic Sports, the twice a week publication of the Ghanaian Graphic Communication Group, doubled from 12 to 24 pages and circulation increased by two times, and the company's main newspaper, the Daily Graphic, experienced a 40 per cent increase in advertising, all because of the Black Stars's performance. Company spokesperson Albert Sam said of the Black Stars's impact, 'I think we will definitely meet our targets, and it will mean more revenue for the company, more expansion and then it will also mean that service will improve, conditions of service for employees will also be better' (Dovi, 2006). This example of the Graphic Communication Group is a snapshot of the potential of what a sports branding 
position can bring to even an impoverished country.

Examples such as Brazil's Culture Cup and Ghana's soccer team are at the extreme ends of the place branding spectrum. Brazil has a sophisticated and mature sports strategy with many parts, heroes, and connections to a number of its cultural symbols. While Brazil is a world-class economic force, it still has significant poverty and is continuing to use sports as a branding tool to help re-image itself. Ghana, on the other hand, is one of the poorest nations in the world with far fewer resources than Brazil, and is faced with even more dire circumstances than other emerging countries. During the 2006 soccer World Cup, however, it tasted the economic power of sports and now needs to find a systematic mechanism to capitalise on it.

\section{Place platform}

The place platform is the newest strategy of the three and involves wholly integrating sports into the design of the place brand. While this platform is only in its earliest stages of development, place brand managers might take a cue from a first-mover in this category, the newly industrialised emirate of Dubai.

Dubai's transition from an oil-reliant trade economy in the middle of the desert to a world class tourist destination has been one of the most impressive in recent place branding history. With a population of only 1.4 million and in a country roughly the size of the state of Maine, Dubai has undergone a transformation with a heavy emphasis on tourism in order to protect itself against the inevitable depletion of its oil reserves. Combining its aggressive real estate developments and state-of-the-art entertainment and leisure activities, Dubai has seen its numbers of visitors explode from 500,000 in 1995 to 6.7 million only a decade later (Khalaf and Wallis, 2006).

The emirate's early success in the tourism industry has stimulated its most ambitious project yet - a $\$ 5.7 \mathrm{bn}$ development called Dubailand, which includes the Dubai Sports City (International Reports, 2005), that is designed to help increase the number of annual visitors to 15 million by 2010 (Khalaf and Wallis, 2006). The plan's strategy appears to benchmark the world's best shopping malls, theme parks, zoos, and sports facilities and to exceed them in both style and substance. Among the many attractions planned is the Falcon City of Wonders, comprised of replicas of the Seven Wonders of the World, and the Snowdome, an enclosed ski mountain for tourists wanting some time on the slopes while in the desert. With something for seemingly every traveller at anytime of the year, Dubai is becoming tourism's version of one-stop shopping where all the major travel and leisure attractions are being imported, consolidated, and distilled into one place.

Perhaps the most innovative component of Dubailand is the Dubai Sports City. Designed on more than 50 million square feet, this $\$ 2.5$ bn project represents an unprecedented marriage between sports and place (Manly, 2006). While sports have always been a central connector in communities, never before have they been institutionalised as a primary place builder. Like a town where an automobile manufacturing plant defines its identity, the Dubai Sports City is defined by sports and plans to use the events and their athletes to connect the residents, tourists, and investors. In addition to the four sports stadiums, there will be shopping malls, condominiums, hotels, training academies, a sports medicine facility, and other sports-themed attractions. In summing up the project, Dubai Sports City chief executive U. Balasubramaniam pronounced, 'Finally, a city within a city, powered by sports' (Manly, 2006).

Dubai Sports City is not the emirate's first venture into sports. Over the last decade, Dubai became a premiere host of events such as the Dubai Desert Classic, the Dubai Tennis Championships, Dubai Rugby Sevens, and many international auto races and horse races. Managing these events was valuable data for testing the brand concept of the Dubai Sports City and provided the evidence to potential residents, tourists, and investors that Dubai was 
capable of serving the sports community. As a result, Dubai has been able to justify raising the stakes in the competitive place wars to not only fulfill its vision of becoming the 'Sports Capital of the Middle East' (International Reports, 2005), but also perhaps the world's centre for sports.

Star power is the principal driver of the Dubai Sports City concept, as global athletes, teams, and federations serve as the headliners for the city's facilities. Manchester United, golf coach Butch Harmon, and tennis guru David Lloyd have invested in training academies in Dubai. In addition, Ernie Els, the popular men's golfer from South Africa, is the designer of The Dunes golf course, which is also the centrepiece of one of the luxurious housing developments that the city has planned. A final star power draw is the International Cricket Council, the governing body of cricket, which moved its headquarters from London to Dubai in order to be more centrally located among its member countries and to capitalise on the new facilities, long-term commitment, and financial support the new city is offering (McSheehy, 2005).

Designed to capitalise on the branding power of sports and attract a segmented group of sports fans and participants, Dubai Sports City is the avatar in redefining the relationship between sports and place and how the two are industrialised. Dubai's place brand-building formula of constructing the sports facilities, adding the housing and amenities of a modern city, and using sports star power to connect all of the elements could signal new developments and innovations in place branding, with sports serving as the anchor. While Dubai has the resources to fund such an elaborate sports city, it still can serve for lesser endowed countries as a lesson plan to brand sports. Many countries have a strong sports history with advantages in facilities and skill development that can be branded as a sports place centre.

The three strategies presented here are intended to provide nations the possibilities for sports place branding. While each nation has different resources and needs, the three platforms and their combinations can offer a blueprint for how to proceed in developing the sports place initiative. The foundations for this development process are discussed in the next section.

\section{SPORTS BRAND POSITIONING}

For those nations that are candidates for a sports branding transformation, there are three issues that they must address: the brand concept, infrastructure, and distribution.

Whether it is the event, team, or place platform, the importance of these issues is similar for any nation considering place branding through sports.

Every place must think of its sports brand as a concept, making sure that it is attractive to them over the long term and has a potential market. The concept must reflect the place's goals and what it can reasonably deliver. It is more likely that Thailand would select a concept built around golf or boxing instead of ice hockey, which has no historical association. Likewise, Finland deciding on an elaborate branding plan to become a major player in the surfing world would not only require too many resources but a major restructuring of its heritage. In addition, if a country has a small population, it would be unrealistic for it to try to compete in a wide range of sports with larger countries such as the United States and Russia. It would be more effective and efficient to selectively choose and develop a niche in those areas.

A good example of a country that has developed and sustained a strong brand is Australia, a country with a 12-month outdoors culture and a history of adventure and vigorous sports activities. In this warm weather country with most of the population on the ocean, the Australians have centred their brand plan on becoming world class swimmers, divers, water polo players, and surfers. Their location assets have made Australia not only a force in water sports on the global stage but also a premiere tourist destination for people looking to engage in these sports. As the Australian case illustrates, a good concept takes into consideration the population, the climate, the potential for 
differentiation, and the importance of the sport's fit with the identity of the place.

A second element of a good sports brand positioning is an understanding and willingness to facilitate its infrastructure. In this context, infrastructure is not only the facilities and transportation, but the ability to provide the structure and organisation to produce talent for the sports brand at all levels. Historically, the most successful countries have very strong youth programmes. ${ }^{5}$ Many of them begin at the grade school level with systematic coaching, strong parental and community involvement, and facilities that are age-based and consistent with building a strong sports brand. Countries such as Canada and Japan have built extensive infrastructures for their branded sports. In other cases, despite a lack of ideal facilities and equipment, the drive so permeates the culture that, for example, Ghanaian kids will play soccer in spaces that barely resemble soccer fields and with balls that are often made of gum tree juice (Duodu, 2005). Whether they are institutionally or culturally driven, places must ensure that they have an understanding of the youth development process and sustain the cooperation of the government, schools, parents, and young people.

A nation that could benefit from developing infrastructure to support its brand is South Korea, which has recently become a dominant country in women's professional golf. The combination of a culture that promotes hard work and focused career development and the surprising victories by Se Ri Pak in the 1998 Ladies Professional Golf Association (LPGA) Championship and US Women's Open has helped stimulate South Korean women's interest in the sport and develop a global identity for this emerging nation (Associated Press Worldstream, 2006; Guregian, 2006). The results have been impressive: At one point during the 2006 LPGA season, four of the top ten money winners on the LPGA Tour were South Koreans and 11 were among the 30 highest ranking golfers in the world (Branch, 2006).

The problem is that the country is not capitalising on its successful golfers by building and supporting a golf infrastructure. Playing golf in South Korea is expensive and is an activity in which only the upper classes participate. Most young, talented South Korean golfers are forced to learn the game on the driving range and move to another country if they want to practice their skills on a real course (Yoon, 2006). As a result, South Korea is not maximising the advantages of its valuable branding assets. It would be more effective for the country to consider developing its own golfers by either subsidising the costs of play or building state-owned courses and facilities that could help retain and develop South Korean golfers as they prepare for international competition. South Korea has some of the most talented golfers in the world, but it is wasting an opportunity to not only generate visibility for the country but also attract tourists, investors, and residents to what could be known as an international centre for golfing excellence.

The final element is distribution. After developing the concept and establishing the infrastructure internally, sports place brands must be launched into the marketplace. In the past, the traditional pipelines of big media, advertising, and public relations were often too costly for emerging places. Today, there are less expensive and innovative ways to reach marketplaces. For example, places can capitalise on the benefits and value of new media and integrate it into their branding plan. Websites, podcasts, and blogs give places a low cost option for reaching targeted audiences and for the first time can communicate an emerging place's vision, goals, and relevance to a global market. Another possibility is that places can focus on attracting foreign investment from global sports leagues and federations with their sports brand concept. All the major sports brands are now sending out emissaries to spread their sport. The National Basketball Association (NBA), for example, with their Basketball without Borders programme, has travelled to foreign nations on community service missions, which simultaneously builds the visibility of the NBA and the countries they visit. ${ }^{6}$ 
An example of an emerging country sports brand that has capitalised on distribution is Jamaica and its fish out of water bobsled team. Immortalised in the movie Cool Runnings (Walt Disney Video, 1993), the country turned an improbable appearance at the 1988 Calgary Winter Olympics into a valuable place branding asset. The brand concept was driven by perspective by incongruity - a bobsled team from a tropical climate - and was an example of the innovation that a country needs to stand out. The Jamaicans finished in last place in that Olympic event, but because of the incongruity of the choice and the underdog storyline that accompanied the team, Disney decided to produce the movie, and as result, Jamaica still benefits from the visibility. ${ }^{7}$

The ability to develop and implement a place brand that is driven by sports requires careful planning and strategic implementation. There are always cases in the sports world where an unlikely athlete or team from a relatively obscure country emerges to win an Olympic gold medal in wrestling or the Rugby World Cup. These could be described as brand-forming moments, which have historically been invaluable in launching a potential sports brand (Rein et al., 2006). For that brand-forming moment, the athlete or team propels the country's name into worldwide media attention, generating global visibility that most other tourist or business attractions cannot provide. The challenge for place brand managers is to capitalise on these brand-forming moments when they occur. More importantly, however, they must prepare a long-term sports strategy with the moment as a foundation that emphasises the brand concept, infrastructure development, and distribution.

\section{CONCLUSION}

In the future, successful place brands will need to integrate the proven strategies of the past with innovations in place communication and marketing. The position of this paper is that an important area for innovation is sports because of their visibility benefits, the emotional heat they establish between places and their markets, and their ability to attract tourists, investors, and residents. The trend of sportsplace development is underway as countries are already capitalising on the appeal of sports teams, events, and the stars that comprise them to their brand. In most cases, however, places are just beginning to develop the infrastructure to support sports-based branding and are searching for the right combination of strategies to make a sports initiative effective.

This paper has suggested three sports branding platform possibilities: the event, team, and place. A place can adopt all three platforms simultaneously, but for places with limited resources, it is more realistic to commit to one or another. This is especially critical since in this increasingly competitive global marketplace, segmentation is vital to the success of sports ventures. Emerging, transition, negatively viewed, and newly industrialised nations that develop a specialised sports platform are more likely to receive a greater payoff than places that choose to spread themselves across too many markets.

The brand choices for a place in this competitive marketplace are rarely easy ones. Even among the traditional brand decision points, tourism, business attraction, resident retention, and product export, there is competition for money and prominence. In addition, there are competing needs for infrastructure, education, health care, environmental concerns and other issues that are considered important to a place's welfare. The advancement of a sports branding culture is inevitably going to vie with legitimate competing concerns forcing all places to sort out their priorities. It may well be that branding strategies in the future are going to be more short-lived and need constant adjustment in a marketplace with such sudden shifts of resources and technological innovations. In this changing environment, the sports branding proposition is another important component to serve either as a centrepiece or a valuable supplement to a place's overall branding position. 


\section{Notes}

1 The World Travel \& Tourism Council predicts that travel and tourism will generate $\$ 6,477.2 \mathrm{bn}$ in economic activity in 2006.

2 In Germany, there have been at least two recent cases of match-fixing. Another match-fixing scandal erupted in Italy in which the nation's most storied team, Juventus, and a number of Italian soccer officials including referees were implicated.

3 The Minnesota legislature approved funding for a $\$ 522 \mathrm{~m}$ downtown Minneapolis stadium for the Major League Baseball team Minnesota Twins. The state legislature also signed off on a $\$ 248.7 \mathrm{~m}$ stadium in Minneapolis for the University of Minnesota Gophers football team.

4 The Minnesota Vikings have also been campaigning for state funding for a new stadium, but the Minnesota legislature did not approve funding for a new stadium during the 2006 Congressional sessions.

5 The United States, Germany, France, England, and Russia have established extensive youth development programmes that are either publicly financed or privately managed.

6 For more information on Basketball Without Borders, see www.nba.com/bwb/bwob_index.html.

7 The 1988 Jamaican bobsled team still has an impact on the country and the sport of bobsledding in general. The team has a page on the Jamaican Web site, see www. jamaicans.com/bobsled.

\section{References}

Agence France Presse (2005) 'China sports market to explode with coming of Olympic games', Agence France Presse, 16 May, Lexis Nexis.

Associated Press Worldstream (2006) 'South Korean women draw on culture to storm international golf', Associated Press Worldstream, 16 June, Lexis Nexis.

Ballparks of Baseball (2006) 'Ballparks of baseball: The fields of Major League Baseball', available at www.ballparksofbase ball.com

Batson, A. (2005) 'Beijing's new party line: China officials train crowds to be more polite, orderly as 2008 Olympics approach', Wall Street Journal, 27 December, p. A13.

Branch, J. (2006) 'South Korea becomes new face of L.P.G.A.', New York Times, 6 July, Lexis Nexis.

Brown, G., Chalip, L., Jago, L. and Mules, T. (2002) 'The Sydney Olympics and brand Australia', in Morgan, N., Pritchard, A. and Pride, R. (eds)' Destination Branding: Creating the Unique Destination Proposition', Butterworth-Heinemann, Oxford, UK,pp. 163-185.

David, A. (2006) 'Trial into Italy's match-fixing scandal wraps up', Associated Press, 7 July, Lexis Nexis.

Dickie, M. (2006) 'Can China meet the highest expectations?' Financial Times, 24 May, Lexis Nexis.

Dovi, E. (2006) 'VOA news: Ghana's football success having economic impact beyond sport', US Fed News, 26 June, Lexis Nexis.

Duodu, C. (2005) 'World Cup, here we come!', New African, December, Expanded Academic ASAP.

Frangos, A. (2004) 'Bigger and better: Pro football teams have ambitious plans for a new generation of stadiums', Wall Street Journal, 20 September, p. R4.
Gratton, C., Shibli, S. and Coleman, R. (2005) 'Sport and economic regeneration in cities', Urban Studies, Vol. 42, Nos. 5/6, May, pp. 985-999.

Guregian, K. (2006) 'Leader of the Pak for Korean women', Daily News Tribune, 29 June, available at www.daily newstribune.com/sportsNews/view.bg?articleid $=73793$.

Hoops Corner (2006) 'NBA teams' arenas', Hoops Corner, available at www.hoopscorner.com/links/team_arenas. html.

Hope, W. (2002) 'Whose All Blacks?' Media, Culture \& Society, Vol. 24, No. 2, March, pp. 235-253.

International Reports (2005) 'Dubai: The sports capital of the Middle East', International Reports, available at www. internationalreports.net/middleeast/dubai/2005/sports. html.

Jackson, S. J. and Hokowhitu, B. (2002) 'Sport, tribes, and technology: The New Zealand All Blacks haka and the politics of identity', Journal of Sport \& Social Issues, Vol. 26, No. 2, May, pp. 125-139.

Kammerer, R. (2006) 'Four arrested in fresh German matchfixing scandal', Associated Press Worldstream, 10 March, Lexis Nexis.

Kang, S. and Fowler, G. A. (2006) 'A big shot in China: To fight Nike, a Beijing sneaker giant aims to turn NBA journeyman Damon Jones into a star', Wall Street Journal, 24 June, p. A1.

Kaszuba, M. (2006a) 'Camden Yards' architect chosen for U stadium', Minneapolis Star Tribune, 9 June, p. 5B.

Kaszuba, M. (2006b) 'County OKs spending plan for stadium', Minneapolis Star Tribune, 21 June, p. 1B.

Kerr, G. and Johnson, S. (2005) 'A review of a brand management strategy for a small town - lessons learnt!', Place Branding, Vol. 1, No. 4, pp. 373-387.

Khalaf, R. and Wallis, W. (2006) 'Adolescent' Dubai shifts focus of its energy inland', Financial Times, 22 May, Lexis Nexis.

Kranhold, K. and Fong, M. (2006) 'Beijing Olympics 2008: Olympic contract games', Wall Street Journal, 16 October, p. B1.

Litan, R. E., Orszag, J. M. and Orszag, P. R. (2003) 'The empirical effects of collegiate athletics: An interim report', August, available at www.ncaa.org/databases/baselineStudy/ baseline.pdf.

Macharia, D. (2005) 'What next for athletics in Kenya?' The Nation (Kenya), 4 April, Lexis Nexis.

Manly, L. (2006) 'Not a mirage, but certainly a sight', New York Times, 9 May, p. D1.

McSheehy, W. (2005) 'Dubai hopes cricket will prove a moneyspinner and visitor draw: Cricket's HQ moves to a Gulf state that sees money in sport', Financial Times, 13 August, Lexis Nexis.

Menez, G. (2005) 'The $\$ 20$ million stadium boom', Sports Illustrated, Vol. 102, No. 20, 16 May, Lexis Nexis.

Miller, J. W. (2005) 'Tab for 2004 summer Olympics weighs heavily on Greece', Wall Street Journal, 11 May, p. B1.

Noll, R. G. and Zimbalist, A. S. (1997) 'Sports, Jobs, and Taxes: The Economic Impact of Sports Teams and Stadiums', Brookings Institution Press, Washington, DC.

Pabst, L. (2006) 'Vikings spent $\$ 745,000$ to lobby for new stadium', Minneapolis Star Tribune, 21 June, p. 3B.

Quirk, J. P. and Fort, R. D. (1992) 'Pay Dirt: The Business of Professional Team Sports', Princeton University Press, Princeton, NJ. 
Rein, I., Kotler, P. and Shields, B. (2006) 'The Elusive Fan: Reinventing Sports in a Crowded Marketplace', McGrawHill, New York, NY.

Riefenstahl, L. (1938) 'Olympia', Olympia-Film, Berlin, Germany.

Roberts, S. (2006) 'Face it: US no longer dominates', New York Times, 4 July, p. D1.

Rosentraub, M. S. (1997) 'Major League Losers: The Real Costs of Sports and Who's Paying for It', Basic Books, New York, NY.

Schimmel, K. S. (2001) 'Sport matters: Urban regime theory and urban regeneration in the late capitalist era', in Gratton, C. and Henry, I.P. (eds)' Sport in the City: The Role of Sport in Economic and Social Regeneration', Routledge, London, UK,pp. 259-277.

Scott, A. (2006) 'AIG scores $\$ 100$ million deal with UK soccer sponsorship', Primedia Insight, 11 April, Lexis Nexis.

Smith, A. (2005) 'Reimaging the city: The value of sport initiatives', Annals of Tourism Research, Vol. 32, No. 1, pp. 217-236.
The Economist (2006) 'Black star tries to rise, again', The Economist, 24 June, Lexis Nexis.

UK Sport (2004) 'Measuring Success 2: The Economic Impact of Major Sports Events', available at www.uksport.gov.uk/ pages/economic_impact_of_major_sports_events.

Walt Disney Video (1993) 'Cool Runnings', Walt Disney Video, Burbank, CA.

World Travel \& Tourism Council and Accenture (2006) 'Travel \& Tourism Climbing to New Heights: The 2006 Travel \& Tourism Economic Research', available at www.wttc.org/ frameset2.htm.

Xiangwei, W. (2006) 'Beijing pulls out all stops for blue skies at Olympics', South China Morning Post, 19 June, Lexis Nexis.

Xinhua General News Service (2006) 'Brazil profits from football to promote culture in Germany', Xinhua General News Service, 7 June, Lexis Nexis.

Yoon, P. (2006) 'Cultural movement: South Korean golfers and those of Korean descent work hard to make their mark at US junior level and begin to dominate on the LPGA Tour', Los Angeles Times, 19 July, Lexis Nexis. 